\title{
SUR TROIS NOUVELLES EIMERIA DE COTIA VERMELHA
}

\section{Par A. CARINI}

Grâce à l'amabilité de M. A. Morsoletto, représentant commercial de notre Laboratoire à Recife, nous avons pu examiner les excréments d'un certain nombre d'animaux du Musée Emile Goeldi, de Bélem (Pará).

Les excréments ont été récoltés en mars 1934 et conservés dans une solution d'acide chromique à 1 pour cent. L'examen microscopique n'a pu être pratiqué qu'après leur arrivée à Saint-Paul, trois semaines après la récolte.

Dans les déjections d'un Cotia vermelha (Aguti aguti), mammifère brésilien de la famille des Caviidær, nous avons rencontré, en grande abondance des oocystes de coccidies de dimensions et d'aspects différents.

On rencontre des oocystes grands et arrondis avec capsule épaisse et brunâtre, d'autres ovales avec capsule plus mince et enfin d'autres petits, ronds, incolores, avec membrane très fine. A côté de ces formes bien différentes les unes des autres, il y en avait d'autres encore avec des caractères peu distincts et difficiles à classer.

Il nous semble certain qu'il s'agit ici d'une infection mixte, déterminée par plusieurs espèces d'Eimeria, et que l'on peut distinguer au moins trois bonnes espèces.

Mais si l'on voulait tenir compte de petites différences dans les dimensions et la forme des oocystes, l'épaisseur, la coloration et la structure de la capsule, etc., on pourrait distinguer plus de trois espèces :

\section{Eimeria paraensis n. sp.}

Les oocystes étaient assez nombreux, arrondis ou légèrement ovales, mesurant de 33 à $40 \mu$ de longueur, pour 30 à $35 \mu$ de largeur.

La capsule, de coloration jaune brunâtre, est épaisse $(2 \mu)$, formée par deux couches, l'extérieure ponctuée à la surface, l'intérieure striée radialement.

Annales de Parasitologie, T. XIII, N $^{\circ} 4 .-1^{\text {er }}$ juillet 1935 , p. $342-344$. 
L'oocyste mûr contient 4 spores ovales de $20 \mu$ de longueur sur $11 \mu$ de largeur.

Dans l'oocyste, il n'y a pas de reliquat de segmentation.
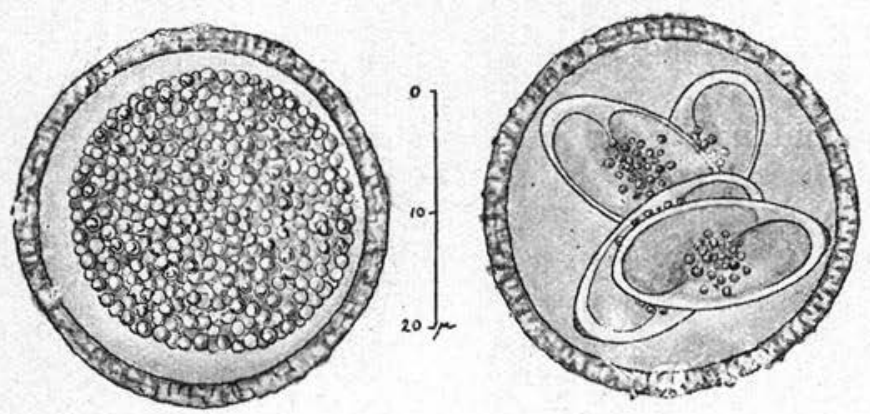

Fic. 1. - Eimeria paraensis n. sp.

Chaque spore présente à une extrémité un corps de Stieda légèrement proéminent et contient deux sporozoïtes et un reliquat granuleux.

\section{Eimeria cotiæ n. sp.}

Les oocystes sont ovales et mesurent en moyenne $29 \mu$ de longueur sur $18 \mu$ de largeur.

La membrane est parfois assez épaisse, très légèrement rugueuse, parfois plus mince et lisse.
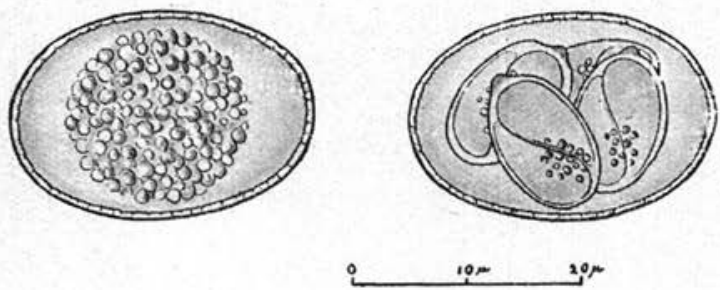

F1G. 2. - Eimeria cotiæ n. sp.

Les oocystes, à membrane plus épaisse, présentent une coloration jaune brunâtre pâle, les autres sont incolores. Le micropyle n'est pas visible.

Les oocystes mûrs contiennent 4 spores ovales de $13 \times 8-9 \mu$.

Chaque spore présente à un pôle un corps de Stieda et contient 
deux sporozoïtes et un reliquat sous forme de granulations éparpillées.

\section{Eimeria aguti n. sp.}

Les oocystes sont sphériques, petits, mesurant $16-17 \mu$ de diamètre.

La membrane est fine, lisse, incolore.

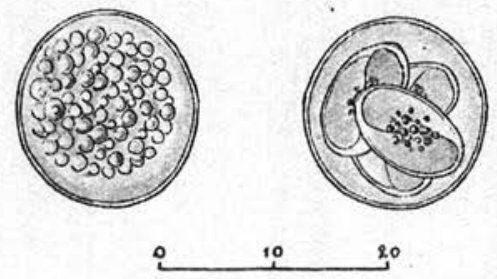

Fıc. 3. - Eimeria aguti n. sp.

Les oocystes mûrs contiennent 4 spores ovales de $10 \times 6 \mu$. Dans chaque spore il y a deux sporozoïtes et un petit reliquat granuleux.

Un petit nombre seulement de ces oocystes est arrivé à maturité.

Caractères différentiels des oocystes de Cotia vermelha.

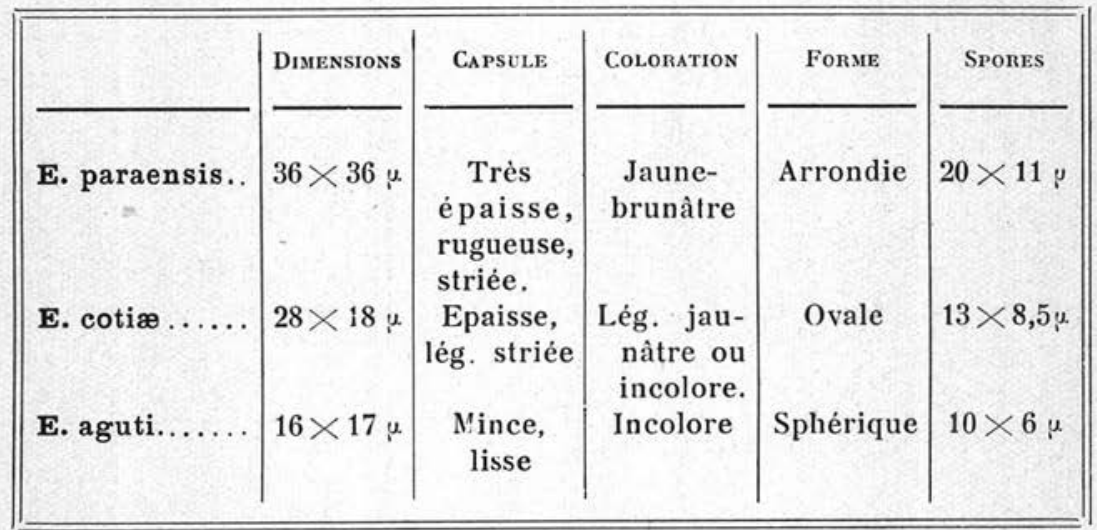

Laboratorio paulista de Biologia, São Paulo (Brésil). 